\title{
LA IMPOSTURA DEL AVATAR: LA BELLEZA INTELIJENTE DE ARTURO VALLEJO
}

Daniel Escandell Montiel Universidad de Salamanca

\section{EL AVATAR: INTRODUCCIÓN}

El avatar es un término que ha entrado en el sector de la cibersociedad de la mano de la construcción de entidades virtuales gracias al uso de recursos digitales en estructuras relacionales de la web, como el uso de sobrenombres o imágenes de diferente tipo que permiten identificar a un usuario determinado en un conjunto de personas, como por ejemplo un foro o un chat. Por supuesto, el término enlaza con referentes asentados en antiguas tradiciones, algo lógico dado que el lenguaje vinculado a la tecnología informática en general, y a Internet en particular, se caracteriza por un fuerte componente metafórico. El avatar es, en sí mismo, un elemento clave dentro de un proceso que puede ser tanto disociativo como una proyección en la que la propiocepción del individuo (como sentido o capacidad del organismo de ser consciente de la posición de sus partes -como músculos, extremidades, etc.- en relación al entorno y a sí mismo) se desplaza desde la persona hasta la entidad virtual como adopción de otros yo digitales, lo que resulta en una fragmentación en el espacio-red, dado que:

Muchas manifestaciones de la multiplicidad en nuestra cultura, incluida la adaptación de personalidades online, están contribuyendo a un replanteamiento general de las tradicionales concepciones unitarias de la identidad en este contexto, las experiencias con la comunidad virtual nos ayudan a elaborar estas nuevas visiones del yo. (Turkle 1998: 51) 
El "yo" es parcial y fragmentado, se divide y multiplica en la proliferación de espacios digitales no vinculados porque tras cada nick, tras cada imagen icónica, hay "otro yo" que no tiene que ser, necesariamente, coincidente con los demás ni con el "auténtico yo", aun cuando todos son -claro- lados diferentes de la misma compleja y poliédrica personalidad de la psique humana. El avatar es un retrato que puede ser visto "hacia adentro, hacia fuera, el rostro como la verdadera máquina del espíritu" (Brea 1991: 106) que es capaz de exteriorizar lo internosubjetivo de un lado del poliedro del individuo, o incluso varios de ellos, cuando no los totalmente simulados.

Si en el hinduismo el avatar es el descenso de la deidad Visnú al mundo de los mortales en una encarnación física, en el contexto tecnológico esto se convierte en la representación del individuo real en un mundo virtual: el ser real "baja" al mundo digital. Más allá de los elementos visuales o lingüísticos directos, en una concepción más completa y global de lo que sucede intelectivamente, el avatar es la proyección del individuo en un sistema social de cualquier índole, sea este un foro, un videojuego en línea, o una red social. En el contexto tecnológico, el avatar es la representación del individuo real en un mundo virtual: es ahí donde el Visnú divino se hace tecnófilo. Eso sí, esta tecnofilia no impone unas destrezas complejas, artes arcanas de ningún tipo, como ya expuso Dibbell:

Four years ago, I sat down at a computer, clicked a few buttons, filled out a text box or two, and in a few short minutes created something it takes the most accomplished novelists years to produce: a fictional character with a life of its own. The life in question, as rich with possible directions and desires as any Shakespeare's protagonist, began unfolding within moments. (Cooper, Dibbell y Spaight 2007: 5)

El término, en el contexto informático-lúdico, se populariza a raíz de su uso por parte de Richard Garriot, cuando este lo introduce -en el año 1985- en su videojuego para ordenador Ultima IV'. En este videojuego, el personaje es denominado bajo el nombre de avatar ${ }^{2}$ de forma genérica, una decisión que parece natural si tenemos en cuenta que el título ofrece la posibilidad al jugador de ir configurando a su gusto el aspecto y la psicología del personaje según avanza en la historia, tanto a través de un sistema de Virtudes (vinculadas a la personalidad), como con complementos, ropa y demás objetos virtualmente materiales. El objetivo último es que el jugador vaya haciendo el personaje a su propia imagen y semejanza. Este uso va potenciándose en propuestas posteriores, como en el vi-

\footnotetext{
${ }^{1}$ En 1979 aparece el videojuego titulado Avatar desarrollado en la Universidad de Illinois sobre PLATO (Programmed Logic for Automated Teaching Operations), un título multijugador en línea que nace como juego sobre texto y luego evoluciona a un sistema gráfico, pero el concepto de avatar se queda en el título y no se aplica a los trasuntos de los jugadores en su entorno virtual. La primera versión se realizó entre 1977 y 1979 por Bruce Maggs, Andrew Shapira y David Sides.

${ }^{2}$ Aunque la saga nace en 1981, no es hasta su cuarta entrega cuando se introduce explícitamente el término: el personaje alcanza el objetivo de convertirse en Avatar, y a partir de ese momento el término se hace genérico para referirse a la representación visual del personaje del jugador en el mundo virtual del título.
} 
deojuego en línea Habitat (1987) o en el juego de rol de lápiz y papel Shadowrun (1989). No obstante, su penetración en el ámbito literario se fecha en 1992, con la novela ciberpunk Snow Crash de Neal Stephenson, la misma en la que el autor populariza conceptos como metaverso, concepto que, en la novela, hace referencia a la marca comercial de un universo virtual -un mundo sintético- conectado mediante una red de computadoras. En ese simulacro-videojuego, los usuarios asumen papeles diferentes dentro de un mundo de fantasía: la proyección del individuo real en ese mundo virtual es denominada avatar.

Si Gibson populariza el término ciberespacio en Neuromancer, Stephenson hace lo propio con avatar en Snow Crash. Se constituye, por tanto, como la proyección del espacio del individuo y del individuo mismo en un mundo que es una simulación de algo inexistente, una hiperrealidad que sustituye el mundo real a través de intermediarios demiúrgicos (Baudrillard 1978: 7-80). Con todo, no debemos desestimar la aportación del propio Gibson, pues, aunque no acuña el término sí es el responsable de describir literariamente, por primera vez, la representación visual de un individuo en un mundo virtual en su novela Count Zero (1986), lo que permite la socialización entre los personajes del relato en el espacio inexistente de la hiperrealidad intangible. Sin embargo, es Stephenson quien introduce el término de manera definitiva, e incluso lo explica en la sección de "Acknowledgments" que acompaña a su novela en las ediciones actuales, reconociendo asimismo que, aunque en el momento de introducción del término en la novela él no lo sabía, no fue el creador de este uso para el término:

The idea of a "virtual reality" such as the Metaverse is by now widespread in the computer-graphics community and is being used in a number of different ways. The particular vision of the Metaverse as expressed in this novel originated from idle discussion between me and Jaime (Captain Bandwidth) Taffe... The words "avatar" (in the sense used here) and "Metaverse" are my inventions, which I came up with when I decided that existing words (such as "virtual reality") were simply too awkward to use... after the first publication of Snow Crash I learned that the term "avatar" has actually been in use for a number of years as part of a virtual reality system called "Habitat"... in addition to avatars, Habitat includes many of the basic features of the Metaverse as described in this book. (Stephenson 1992: 269-270)

Tradicionalmente, el avatar se ha empleado para hablar, en no pocas ocasiones, de la imagen empleada por el usuario en un entorno virtual, esto es, la proyección gráfica del mismo más que la nominal, aunque se extiende cada vez más la concepción de avatar como el conjunto de rasgos personales de un individuo en un sistema social virtual: el tecnocuerpo del que habló Javier Echeverría (2003: 18). La sociedad digital se asimila a un proceso lúdico de virtualidad alejado, independiente, del juego puro tradicional: "the utopian dream of liberating play from the game, of a pure play beyond the game, merely opened the way for the extension of gamespace into every aspect of everyday life" (Wark 2007: 16), fusionando así la ficcionalidad lúdica y la irrealidad de la propia vida real, dado que, justamente, "la irrealidad de los juegos denuncia que lo real no lo es aún. Son ejercicios inconscientes de la vida justa" (Adorno 1951: 237). 
Limitarnos a lo visual, a la entidad figurativa proyectada mediante recursos iconográficos, en el individuo virtual sería tan superficial como hacerlo en el mundo real. El avatar entendido limitadamente como esa representación icónica es una proyección fractal (deliberada o intencionada) que produce un sesgo en la información aportada (al no haber más contexto para reforzar el significado de esa imagen significante). Por ejemplo, un usuario que haya escogido una imagen de una actriz puede haberlo hecho por admiración (o por aversión, según la intencionalidad de la fotografía), porque le parece atractiva, buena intérprete, o un modelo que alcanzar... y aun así seguiríamos sin saber si ese individuo es masculino o femenino. Lo mismo se puede decir del apodo. Sin embargo, combinados, constituyen una unidad, ayudan a transmitir un mensaje de entidad psicológica mucho más completo... pero igualmente sesgado. El avatar, como máscara de la persona que se esconde tras el mismo, puede ser una imagen, un personaje completo, o solo un seudónimo. Mark Stephen Meadows rememora la experiencia de la primera creación de un Nick cuando recibió su módem y se le solicitó un nombre de usuario en 1992:

Part of the software was a subscription to America Online. I popped in the floppy disk and was asked for my screen name.

On a moment's inspiration I typed in PigHed. A friend that day had called me pigheaded, which I am, and pigs have always attracted me because they seem been horrific and adorable [...]. I would have typed in Pig Head, but the system only allowed six characters, so I typed in what I did and, having set a sign on my shiny new virtual forehead, I set out to explore.

AOL's architecture was chartroom based. The interface consisted of boxes with texts in them that were organized so that groups could form around particular discussion topics. (Meadows 2008: 9)

Es el individuo el que escoge qué le representa y, por tanto, decide qué parte de su personalidad (real o impostada) se proyecta ante los demás: es una máscara. Por otro lado, el hecho de que el individuo esté tras la máscara que es el avatar -lo que implica un conjunto de rasgos identificativos virtuales transmutables (que, además, pueden ser diferentes de una red a otra, permitiendo un tratamiento independiente en cada uno de su propia proyección personal)- posibilita que este se centre más en su propia identidad, y no tanto en la homogeneidad colectiva, exaltando valores idiosincrásicos. Esto nos lleva al culto al ego; es posible incluso que defienda ideas que no respaldaría en público, lo que también ha sido vía de escape para diferentes tipos de actitudes éticamente rechazables, cuando no abiertamente delictivas, aprovechando el anonimato y/o la cultura del alter ego en la red. Dejando fuera de la cuestión a las mentes enfermizas y a los delincuentes, lo que nos encontramos es que los individuos recurren a una fragmentación de su personalidad, pues proyectan en la red partes concretas de ellos mismos gracias a la facilidad de enmascaramiento que proporciona el entorno social digital.

El avatar se constituye, por tanto, como el ente virtual sobre el que se ejerce la proyección del espacio del individuo -y del individuo mismo- en un mundo 
que es una simulación de algo inexistente, una hiperrealidad que sustituye el mundo real a través de intermediarios demiúrgicos. Ante la red se construyen personalidades fragmentadas que son el resultado de un filtro muchas veces autoimpuesto por los usuarios. La propiocepción muta para dar pie a "otros yo": es ahí donde la separación entre el avatar y el enmascarado que se esconde tras el mismo puede alcanzar su punto álgido, como resultado de anular la suma de las partes que conforma la personalidad de cada uno de los individuos. Esto tiene como consecuencia desde la construcción de personalidades muy fragmentadas, fruto de la autoimposición de roles o estereotipos, hasta una impostura consolidada de proyección parcial.

El reflejo avatárico será más bien fruto de la interpretación de un papel. Eso explica que, en comunidades de usuarios, nos encontremos con casos de creación de múltiples identidades, es decir, "habitantes" de una misma comunidad que esconden a una única persona. Esta multiplicación puede deberse a la referida fragmentación para enfrentarse con alguien de esa misma comunidad-de manera ofensiva, aunque no solo por dar rienda suelta al insulto- sin que se asocie ese avatar conflictivo ni con su persona real, ni con su avatar habitual. Lo mismo se aplica a la exposición pública de intimidades potencialmente vergonzantes, incluso cuando la proyección personal en esa comunidad virtual es una máscara avatárica. Es decir, ya son anónimos de base, pero crean una segunda divergencia en esa comunidad, en la que están por el proceso de asociación de identidad con el tecnocuerpo del avatar, debido a una cierta "reputación" de la máscara avatárica que han vestido. En el ámbito tecnológico interactivo, los avatares se han popularizado en el ocio electrónico, y se encuentran en múltiples variantes en entornos virtuales de tipo metaversal, como Second Life, y también en las interfaces de las consolas de videojuegos.

Partiendo de esta representación visual, complementada con un apodo o seudónimo y otro tipo de información personal, los individuos llegan, ya no a una proyección de sí mismos en el mundo virtual, sino a la constatación plena de un tecnocuerpo identificado con una imagen, un personaje poligonal, o un seudónimo. El avatar puede, por tanto, ofrecer diferentes caras, pues es la proyección deseada, sesgada, que el creador del mismo ofrece de sí mismo. Es una nueva "prótesis" del ser humano (Broncano 2009). Una prótesis en la medida en que el ser humano genera una dependencia de su instrumentos generados a partir de su habilidad intelectual, herramientas que se convierten en inseparables y que le permiten superar sus limitaciones físicas. Esos objetos se acomodan, se amoldan a la vida cotidiana y pasan a formar parte del ser humano como prótesis ortopédicas esenciales, ya sea en la forma de calzado, vivienda o cocina (distinguiéndose de las simples "herramientas", pues estas son únicamente de uso ocasional, no necesario ni constante). No solo eso: son prótesis que van más allá de lo material y se constituyen también en prótesis culturales, destinadas a cambiar el modo de pensar, como por ejemplo la lengua, la escritura o las matemáticas (Broncano 2009: 20-29), ya que nuestra especie ha dejado de vivir en un contexto de oposición entre la naturaleza y la cultura: estas se han hibridado desde siempre como suma de lo material y lo inmaterial (Latour 1991). 
Ante las nuevas prótesis del tecnocuerpo debe darse un proceso de adaptación. Si el tecnocuerpo -cíborg de carne virtual- lleva al propietario a un nuevo espacio en el que se ha de habitar inmaterialmente -un no-lugar de la supermodernidad descrita por Marc Augé (1992)-, podemos prever también que derive en desarraigo, exilio y extrañamiento. El avatar lleva al autor a un nuevo espacio que va más allá del alter ego ${ }^{3}$, y su objetivo no es sustituir una función, sino que está generando otras nuevas en la red como resultado de una reformulación biocultural. Es el fruto de un nuevo entorno socializado y culturalizado en segundo estadio y que va más allá del primero, como resultado de la influencia del ser humano sobre la naturaleza, en un proceso de intervención mediante sus acciones (Broncano 2012: 95). En esa misma línea se avanza hacia el hombre posorgánico, esto es, el hombre que obtiene su poder no de una superioridad orgánica, sino de un dominio del software informático como parte de un cambio de paradigma sobre los elementos de poder.

\section{NARCISO ANTE EL FLUJO DE DATOS}

Más allá de las implicaciones políticas y de establecimientos autoritarios, el paso hacia el mundo posorgánico y la proyección del autor en el mismo a través de la imagen fragmentada del avatar es lo que debe ser tenido en consideración. Es un proceso de melancolía que puede derivarse, como se apuntaba antes, de la sensación de desarraigo al trasladarse al espacio inexistente (virtual) y su distanciamiento de los paradigmas culturales anteriores. "La melancolía es un estado característico de la modernidad cultural, de una época que se pensó a sí misma como exilio y ruptura con lo no moderno, con la tradición" (Broncano 2009: 2425) y, como tal, en este momento el autor que se ha sumergido en un nuevo paradigma se encuentra en la frontera de dos mundos que chocan: la literatura tradicionalista y todo su aparato industrial y cultural (crítica, editorial, publicidad), frente a los nuevos modelos en red. Son cambios culturales que resultan previsibles como parte de la tradición de renovación, de imposición de lo nuevo sobre lo viejo, ya que:

Cada forma cultural, una vez creada, es minada por las fuerzas de la vida. Tan pronto como una forma ha accedido a un desarrollo insuperable, comienza a revelarse la siguiente forma; esta, tras una lucha que puede ser más o menos prolongada, triunfará inevitablemente sobre su predecesora. (Simmel 1918: 316)

Por otro lado, el autor de blogs muestra una tendencia narcisista que le conduce a sociedades microgrupales en las que revolotean en torno a intereses

\footnotetext{
3 Se vincula, por tanto, con los morfos descritos por Mark Dery. El avatar se convierte en la proyección tecnocorpórea y, como tal, crea una sintonía entre la propiocepción y la imagen -incluso cuando es puramente virtual- del individuo, algo que sucede también en el mundo físico mediante las alteraciones que se derivan de la cirugía estética y que Dery ilustra con el caso de la transexualidad (1992: 253-255). Esto no solo se limita a mundos sintéticos (Castronova 2005) como los de los videojuegos y entornos de realidad (o alteridad de la realidad) simulada, sino también a redes sociales, foros, etc.
} 
comunes, que son lo que les hace ser parecidos, al tiempo que desarrollan actitudes extimistas ${ }^{4}$ (hacer público lo íntimo), en las que, pese a todo, el acto de comunicación es más importante que lo comunicado, generando una fascinación por el propio medio. Esto ha penetrado en esferas de los medios tradicionales:

En parte porque no hay muchos buenos escritores en la blogosfera, y en parte porque "a cierta distancia, toda vida es de pena", como dice el poeta Francisco Brines, la mayoría de los blogs personales se caracteriza por la insustancialidad; la segunda, que hay un interesante fenómeno de espejos entre los blogs y los otros medios: la página de Bitácoras.com tiene una sección en su página de inicio donde va colgando la repercusión que tienen los blogs en medios "exteriores". (Mora 2006: 56)

En la esfera digital, el blog ha superado ya la fase en la que su función principal era la de ser un diario personal y poco o nada más, gracias al avance que le ha inyectado su dinamismo natural. Este dinamismo lo impulsa a un cambio continuado cuanto mayor es el número de blogs creados $y$, por tanto, mayor es el número de personas que los emplean como método de publicación digital. El bloguero extimista hace de la bitácora su diario personal no ficcional, su lugar de reflexión propio; el escritor-periodista usará el blog como nanomedio; y el escritor creará obras fictivas. Únicamente los dos primeros casos han conseguido suscitar un interés amplio en los medios generales que no solo crean sus propios sistemas de blog, sino que utilizan los blogs como testimonios. No es tan extraño encontrarse con medios que emplean blogs como fuentes de información, de la misma manera que las redes sociales se han convertido en sustitutos de la nota de prensa.

El autor sigue la tendencia general de Internet (y que incluso se da en redes sociales más o menos cerradas como Facebook) de esconderse tras un seudónimo, obtiene así una libertad mayor: la distancia entre su "yo real" y su "yo escritor" puede crecer porque no hay una asociación directa, se llena de libertad y puede adoptar los cánones de Internet por encima de los de la literatura, lo que conlleva situaciones en las que los autores se otorgan el derecho de trabajar con una libertad sin precedentes sobre los textos de los demás, anulando el concepto clásico de autoría, pues:

Los textos de los otros son memes ${ }^{5}$ también y están en su derecho de "especie" (ojalá pronto en vías de extinción) de reutilizarlos como si fueran pura información y no conocimiento artístico o, según el caso, sabiduría. Si tenemos en cuenta que, según la teoría aristotélica, los textos son una imitatio de la realidad, nos encontramos con que los textos posmodernos son un[a] Realidad

\footnotetext{
${ }^{4}$ Concepto de origen lacanista que ha sido usado más habitualmente por psicólogos y psicoanalistas (Tisseron 2001) que, como deja intuir el juego de palabras, significa hacer pública la propia intimidad a través de un medio de comunicación de masas, ya sea la televisión con los reality-shows (y afines), o Internet con los blogs y las redes sociales. En el contexto literario-digital contemporáneo ha sido aplicado por Laddaga (2007) y Sibilia (2008).

${ }^{5}$ En las teorías sobre la difusión cultural, la unidad teórica de información cultural transmisible de un individuo a otro o de una mente a otra (o de una generación a la siguiente). El término
} 
Virtual literaria, una mímesis de segundo grado: imitación de otra imitación. (Mora 2006: 167)

No solo el texto es esa mímesis de segundo grado a la que alude Mora, pues el propio autor ya no se proyecta sobre la obra como un reflejo de sí mismo, sino de la personalidad, posiblemente fragmentada, que genera en el blog. Esto puede suponer una liberación, y quizás a través de la fragmentación avatárica, la distancia impuesta entre ese filtro que es el avatar y quien está tras éste (expresada físicamente por la pantalla del ordenador y por la deslocalización y ubicuidad de la red), sea cada vez mayor. Al mismo tiempo, la reutilización de materiales y el cambio en la perspectiva del creador modifican el concepto de autor "original": "por lo tanto, anacrónicas son también [...] sus reclamaciones de autoría, su vindicación de propiedad intelectual, su salario" (Mora 2006: 167), algo previsible puesto que es la perspectiva misma del bloguero. Son, en plena acción, los semionautas de Bourriaud:

\begin{abstract}
Who produce original pathways through signs. Every work is issued from a script that the artist projects onto culture, considered the framework of a narrative that in turn projects new possible scripts, endlessly. The DJ activates the history of music by copying and pasting together loops of sound, placing recorded products in relation with each other. Artists actively inhabit cultural and social forms. The Internet user may create his or her own site or homepage and constantly reshuffle the information obtained, inventing paths that can be bookmarked and reproduced at will. (Bourriaud 2002: 18)
\end{abstract}

Esto puede ser ofensivo para algunos ${ }^{6}$, pero el autor de literatura en blog, en particular asume que el acto de creación en línea es un acto de comunicación en el que la obra se regala a la comunidad, muchas veces anónimamente, porque eso es también parte del juego: esconderse tras la máscara del avatar como en un baile de máscaras o en un juego del escondite, sobre todo cuando el autor ya puede ser reconocido, sea por los agentes culturales tradicionales o los nuevos generados en la Web 2.0. Mantener el disfraz, el avatar, en el que se esconde es un triunfo, un ejercicio creativo equiparable al de la gestación literaria y, de hecho, inseparable de esta. No es publicar una novela bajo un seudónimo, sino

es acuñado por el genetista Richard Dawkins en 1976 en el libro The Selfish Gene proponiendo un modelo evolutivo de desarrollo y de cambio culturales basado en la replicación de ideas, saberes y demás información cultural mediante la imitación y la transferencia, por lo que su definición de meme postulaba cambios biológicos reales de las neuronas cerebrales cuando los memes infectan el cerebro (Lankshear y Knobel 2003: 211). Esto último fue discutido intensamente, y en 1999 Dawkins revisó su teoría retrospectivamente, señalando que el término era aplicable a canciones, eslóganes, modas...

${ }^{6}$ En el ámbito de la literatura impresa hay recientes ejemplos de esta situación. Los más populares en los últimos tiempos han sido en torno a Jorge Luis Borges y las demandas de la viuda María Kodama, cuyas amenazas hicieron que Alfaguara retirara el libro El hacedor (de Borges). Remake de Agustín Fernández Mallo a finales de 2011, alegando la empresa que la retirada se hizo voluntariamente (Rodríguez Marcos 2011). En un caso similar contra el argentino Pablo Katchadjian por su libro El Aleph Engordado, este sí llegó a juicio con acusaciones de plagio, pero los cargos fueron sobreseídos (Tomas, 2012). 
generar un autor virtual que se enfrenta en el día a día al escrutinio de los lectores y debe lidiar con estos: desde el momento mismo en que se sospecha que el autor no es quien dice ser, desvelar el engaño y hacer que las máscaras dejen ver el rostro real es parte del ejercicio de lectoautoría que establece el receptor de la obra:

The writer is then the protagonist, personifying the role as would an actor in a process of assimilation which transforms the main character in an avatar. There is, hence, a strong hoax component in the narration and creation of the protagonist so as to deceive the reading public, always masking the writer: to hide his identity, and to convince the public that what they are reading is actually being written by an anonymous blogger, just as any else, are some of the main artistic objectives of the blognovel, which we cannot and must not confuse with the serial novels published in blogs. (Escandell 2010b: 128)

En cualquier caso, el lector de un blog no debería sentirse ofendido por el hecho de que el autor opte por esconder su identidad real a través de un avatar, pero sí puede buscar sacar a la luz su personalidad real; no por malicia, sino porque es un reto intelectual al que posiblemente ya ha estado expuesto en otros soportes de Internet. Hasta ahora, un lector podía afrontar una obra como una novela sabiendo que era una ficción con autor reconocido, anónimo o tras un seudónimo, aunque siendo conocedor de que era una ficción, desde el momento en que lo adquiría en la librería alejado de los estantes (y listas de ventas) de no ficción; ahora, esto ya no es así. La blogoficción en general -y con ella las blogonovelas- es fruto de la pulsión por esconder la ficción disfrazándola de aparente verdad, por lo que el lector va a encontrarse en la situación de no saber realmente si está asistiendo a la obra fictiva de un autor, o a la pulsión extimista de un usuario anónimo en el océano de Internet. Se trata de la "suplantación de lo real por los signos de lo real" (Baudrillard 2007: 11), y un "fingir tener lo que no se tiene" (12), que puede, asimismo, destruirse al ser descubierta. Se reproduce, entonces, la ironía de la etnología: al observar el objeto de estudio, este se altera y destruye en su estado natural, haciendo imposible su contemplación pura (20-22). No obstante, Casciari sugiere que "más tarde, cuando el lector ya esté habituado y no le importe -cuando hayamos conseguido 'transportarlo'- podremos quitar algunos velos sin peligro" (2006: 174), hasta tal punto que algunas de sus obras han sido desenmascaradas antes de su conclusión $y$, sin embargo, han seguido adelante hasta el desenlace.

\section{HoAX ANTES QUE AVATAR BLOGOFICTIVO}

Por supuesto, el uso del avatar como recurso literario para la creación de personajes impostados tiene precedentes en comportamientos sociales de la red, siendo particularmente significativo el caso de Kaycee Nicole Swenson, una adolescente moribunda que tenía un blog, pero que jamás existió:

On May 14, 2001, a popular weblogger died of an aneurysm related to treatments for leukemia. She and her mother had been chronicling their ex- 
periences for almost a year in their journals, Living Colours [...] and Journey Towards the Rainbow [...]. Webloggers mourned the passing of one of their own, writing their thoughts in their weblogs, flooding her mother with condolences and posting messages about he run message boards. But a few observers had doubts, and their questioning sparked a storm of controversy leading to a full confession: the writer of the weblog, Kaycee Nicole, was not a real person. (shirobara 2001)

Todo empezó en 1998. La hija de una ama de casa residente en Kansas (EE. UU.) creó, junto a algunos amigos, un perfil para una chica que no existía en la web College Club (en la actualidad <http://www.teen.com>) usando la foto de una jugadora de baloncesto en un equipo local. No hay constancia de que la acción de los menores fuera a más; sin embargo, cuando Debbie Swenson descubrió en 1999 lo que había hecho su hija, decidió coger ese perfil y darle "vida" en forma de una adolescente enferma de leucemia que era una pequeña estrella local en su equipo deportivo.

Durante la encarnación de este personaje, Debbie estableció una relación próxima con los responsables de la web College Club y generó un amplio círculo de amistades digitales, en buena medida por las muestras de apoyo que recibía por su enfermedad. Como contaba en multitud de ocasiones, Kaycee tenía leucemia $y$, aunque en un primer momento había obtenido resultados con el tratamiento consiguiendo la remisión del cáncer, este finalmente había regresado.

El personaje, que había nacido en un contexto de web social, se pasó al blog en el año 2000, cuando uno de los amigos del personaje-Randall van der Woning, al que, lógicamente, solo conocía digitalmente- se ofreció a crearle un blog, Living Colours, que ya no existe. En el blog se contaban las hospitalizaciones, problemas e ilusiones de la joven, normalmente ella misma -es decir, por el propio avatar-, pero a veces también por su madre, llamada Debbie (pues la autora asumió también el papel de la madre de una hija enferma).

La bloguera, que contaba su vida y el devenir de su enfermedad, alcanzó definitivamente la fama cuando fue entrevistada telefónicamente el 10 de agosto de 2000 por el prestigioso The New York Times. El artículo se publicó asumiendo que Kaycee Nicole Swenson era un personaje real. En la misma, Kaycee se definía como una chica en el último año de instituto, llena de ilusión por empezar la universidad al año siguiente. Fue en mayo de 2001 cuando el mismo rotativo publicó un artículo en su sección de tecnología explicando cómo todo había sido un fraude (Hafner 2001).

El weblog propició el nacimiento de varios movimientos de apoyo en la red, generando toda una comunidad de seguidores que ignoraba que Kaycee era un personaje inventado. La debacle del personaje empezó en abril de 2001, cuando comentó que su hígado estaba fallando. Entonces, Randall van der Woning, el chico que le creó el blog, insistió en visitarla pues estaba realmente preocupado por ella, ignorando que no era una persona real. Aunque inicialmente Debbie consiguió aplazar el encuentro, la madre de Kaycee llamó entre lágrimas a Randall el 15 de mayo de 2001 para contarle que su hija había muerto por un aneurisma. Simultáneamente, se publicada en el blog un mensaje comunicando la muerte de 
la joven: "Thank you for the love, the joy, the laughter and the tears. We shall love you always and forever. Kaycee Nicole passed away May 14, 2001, at the age of 19" (Hammond 2001).

La dramática historia de la enfermiza Kaycee había llegado a su fin, aunque pronto empezaron las sospechas. Aunque en el pasado Kaycee había aceptado regalos físicos que le habían sido remitidos por correo, ahora no había rastro alguno de dirección postal. Además, Debbie le dijo a Randall que Kaycee había sido incinerada y que ya había tenido lugar el funeral apenas dos días después de su fallecimiento. Cuando esto trascendió entre la comunidad de seguidores, una bloguera, Saundra Mitchell, publicó un artículo en el que evaluaba casos de personas que habían fingido enfermedades en Internet. Se inició entonces un torrente de especulaciones, observaciones sobre elementos peculiares de este caso y, además, múltiples usuarios comentaron que el estilo de escritura de Kaycee y de su madre era virtualmente idénticos. Se señaló también que Kaycee hacía referencia a elementos de cultura popular (como canciones) de los años 70, algo que parecía poco coherente con el aparataje cultural de una adolescente.

Finalmente, el 19 de mayo Debbie Swenson contactó telefónicamente con Randall y le confesó que Kaycee no era su hija biológica, sino una hija adoptiva y le pidió que no desvelara esta información. Sin embargo, al no hacerlo, la comunidad de usuarios de Internet siguió investigando y se descubrió que eso era también mentira. La confesión real en la que Debbie admitió que absolutamente todo había sido falso tuvo lugar el 20 de mayo de 2001: Randall fue quien publicó en el blog Living Colours el mensaje público confirmando que Kaycee Nicole no había existido jamás. Debbie se defendió alegando que el personaje estaba basado en tres personas diferentes que había conocido y que habían muerto por diferentes tipos de cáncer.

Aunque este suceso ha sido considerado un precedente de la blogoficción, hay que tener en cuenta que popularmente se ha vinculado con aspectos propios de patologías asociadas al síndrome de Münchhausen por Internet. Sus características fueron descritas en 1998 (Feldman, Bibby y Crites), aunque no fue hasta 2000 cuando el doctor Feldman le puso ese nombre en el artículo Munchausen by Internet: Detecting Factitious Illness and Crisis on the Internet ${ }^{7}$. Consiste en la traslación del clásico síndrome de Münchhausen al entorno de las comunicaciones virtuales. En este caso no es necesario enfermarse de verdad (en la patología clásica, el paciente puede incluso producirse lesiones o somatizar síntomas), sino que basta fingirlo en entornos de comunidades digitales, como una red social, para obtener la respuesta de apoyo ante la enfermedad que persiguen las personas afectadas por este síndrome. De hecho, el "incidente" de Debbie Swenson estaría, en todo caso, más cerca de un hipotético síndrome de Münchhausen por poderes, haciendo que enferme una persona próxima, solo que, en esta ocasión, era un personaje ficticio creado en Internet por ella mismå.

\footnotetext{
${ }^{7}$ Debo agradecer al Dr. César Serrano, del Brigham and Women's Hospital de Boston, su orientación y consejo para las observaciones relativas a aspectos médicos en este artículo.

8 El síndrome de Münchhausen implica fingir síntomas que no se tienen con conciencia plena de
} 
Cabe preguntarse, entonces, si esta proyección avatárica respondía a una voluntad creativa con intencionalidad fictiva o si era una pulsión derivada de una enfermedad. No podemos negar que recoge aspectos que serán considerados relevantes para la definición de la blogonovela y parte de la blogoficción, destacando la creación de un personaje avatárico y la impostura mantenida hasta el desenlace. Con todo, la historia que se desveló tras descubrirse el engaño y el hecho de que la propia autora eliminara el blog poco después, parecen apuntar, más bien, a intenciones alejadas de la creación y exploración literaria o ficcional. Otra cuestión, por supuesto, es que, fuera de esa intencionalidad, este caso represente una nueva senda para la realización de obras autofictivas o de desarrollo de una literatura sustentada en el aprovechamiento de los parámetros de publicación y creación de identidades digitales.

En esa misma línea, es importante señalar que la autora "ni durante ni después de terminada la historia ha reclamado su autoría sobre el producto ni ha mostrado interés alguno en resaltar el carácter artístico de su performance" (Cleger 2010: 352-353), aunque en sentido contrario se ha defendido el recurso a la suspensión "involuntaria" de la credulidad como parte del proceso de recepción del texto:

Why shouldn't Kaycee continue to be a symbol of gallantry? We take heart from fictional people all the time. Movies, books, TV shows; we use them to think about human values. Narratives help us work through abstract notions like loss and pain and love and grace.

Seems to me Debbie Swenson was an artist using the tools at her disposal. She was a writer who wanted an audience, and she found a way to get one. Sure she lied a little -have you never lied to get a job you really wanted? Did it even matter once it was clear that you could do a good job?

Everyone agrees that Debbie Swenson did a good job. Why should people feel cheated? Their emotions were real; their tears were real; the sense of hope they experienced was real. Was that not worth the unwilling suspension of disbelief? (Carroll 2001)

Desde luego, solo mediante una fuerte suspensión de la incredulidad es posible aceptar como ciertos algunos de los -en ocasiones, delirantes- argumentos de las blogonovelas, aunque la cuestión reside en si esta suspensión es voluntaria (el receptor sabe que es una obra fictiva y decide entrar en el universo literario) o involuntaria. Esto último supondría que no se realiza un pacto de ficción con el autor, pues no es posible asumirlo en la medida en que no se sabe de ante-

\footnotetext{
manipulación para conseguir un objetivo concreto, por lo que no es un proceso delusivo como la hipocondría. En el caso del síndrome de Münchhausen por poderes, se obliga a una persona a fingir síntomas. En el síndrome de Münchhausen por Internet se fingen esos síntomas, pero no hay razón para impostarlos realmente porque la comunicación es virtual. En el caso de Debbie Swenson, puesto que no hay una persona real sobre la que se ejerza el síndrome, no puede tratarse stricto senso de ninguna variante de esta enfermedad, sino, en todo caso, de una suerte de impostura consciente o inconsciente del síndrome de Münchhausen por poderes en Internet, más por los paralelismos con la descripción aportada por el Dr. Marc Feldman que por un caso real del síndrome.
} 
mano que la obra es ficticia. Luego, ¿es el planteamiento de la historia de Kaycee tan delirante como aceptarse solamente tras una suspensión (in)voluntaria de la incredulidad? De la misma manera, hubo una gran comunidad de visitantes que aceptó como real su historia, así que quizá entre en juego un comportamiento gregario en el que se asume que, puesto que un colectivo da por ciertos unos hechos, esos se conciben automáticamente también como reales. Entendemos que la blogonovela "solo es posible cuando ese 'falso yo' se convierte en encarnación real de un tecnocuerpo, proyección avatárica del bloguero/autor al otro lado de la fibra óptica" (Escandell, 2010a: 41), derivada de una concepción teatralizante del papel del autor que consiste en un acto performativo y figurativo, donde este debe engañar a sus propios lectores, haciendo de la propia narración un ejercicio de hoax .

Quizá no había una intención explícita de crear literatura en el "fraude" de Swenson, aunque esa voluntad de asumir una impostura es, definitivamente, compartida con la blogonovela. Esta, a su vez, basará su relación con los lectores no en la firma de un pacto de ficción, sino en el poder nutrirse de su credulidad. Sea como fuere, sí es cierto que el caso de Kaycee Nicole, inspiró el mismo mes que se supo la verdad de la creación de Plain Layne (el blog ya no existe), la historia de Layne Johnson, una mujer que había conocido a un bailarín español y se había enamorado perdidamente de él. Durante los dos años de su blog (20012003), acogió a la hija embarazada de su prima y posteriormente al bebé, conoció a sus padres biológicos, fue violada en México, conoció a una compañera de trabajo de la que se enamoró, inició una relación sentimental y se prometió (aunque luego se rompió la relación), etc. Pero Layne no era real: todo fue fruto de Odin Soli, novelista y abogado especializado en temas latinoamericanos, administrador de bases de datos y gestor de webs. De esta manera, aunque fuera solo como una influencia del poder de convicción, de sustitución del espacio personal por personajes ficticios, observado a raíz del caso de Swenson, Soli exploró el blog como vía para ofrecer un culebrón que atrapó al público:

While everyone flounders around clumsily experimenting with fake Friendster profiles and finding their voices on blogs and journals, this guy has created two entirely plausible and entertaining online characters, fleshing them out over a series of months in living, evolving narratives. A round of applause is in order here. (Kottke 2004)

El avatar es la ejecución virtual del hombre posorgánico, sometido a una tecnología virtual como proyección última del personaje creado por el autor para su narración en la blogonovela. No obstante, el blog demanda al escritor que el personaje exista no solo dentro de la realidad de la ficción literaria, sino en el mundo real de los lectores, para interactuar con ellos, y, por tanto, debe tener una

\footnotetext{
${ }^{9}$ Voz inglesa referida a la distribución de información falsa a través de Internet, con el objetivo de divulgar lo máximo posible el engaño, hasta tal punto que algunos se han convertido en memes o leyendas urbanas. Aunque pueden esconder intereses como la recolección de datos (cuentas de correo electrónico), o iniciar una campaña de publicidad viral, no es extraño que algunas nazcan con la simple intención de confundir a los crédulos.
} 
entidad propia, yendo más allá de todas las implicaciones que se puedan realizar entre este concepto y el del seudónimo.

\section{LA MISS INTELIJENTE}

En el proceso de construcción avatárica, el autor se ve obligado a construir el personaje como un actor construye un papel para una obra teatral, adoptando el rol de su avatar para interactuar con los lectores y construir un entorno ficticio pero verosímil que sea el contexto vital del personaje, algo que deberá ser asumido como cierto o como parte del pacto de ficción por los lectores. El recurso creativo es dar voz a un personaje que es impostura y máscara, ya que debe asumirse en los contextos de uso que construyen la producción de presencia digital. Esto implica no solo una modificación del estilo y hábitos de escritura para llevar a cabo el fingimiento de ser otra persona, sino también aprovechar los recursos y estrategias de producción de espacio personal que ofrecen las bitácoras, ya que:

La función-autor no es en efecto una pura y simple reconstrucción de segunda mano que se hace a partir de un texto dado como un material inerte. El texto lleva siempre en sí mismo un determinado número de signos que remiten al autor. Esos signos son bien conocidos por los gramáticos: son los pronombres personales, los adverbios de tiempo y de lugar, la conjugación de los verbos. Pero hay que señalar que esos elementos no actúan de la misma manera en los discursos que están provistos de la función-autor y en los que están desprovistos de ella. En estos últimos, tales shifters remiten al locutor real y a las coordenadas espacio-temporales de su discurso (aun cuando pueden producirse algunas modificaciones: como cuando se relatan discursos en primera persona). En los primeros, en cambio, su papel es más complejo y más variable. Sabemos bien que en una novela presentada como el relato de un narrador, el pronombre de primera persona, el presente del indicativo, los signos de la localización nunca remiten exactamente al escritor, ni al momento en que se escribe ni al gesto mismo de su escritura, sino a un alter ego cuya distancia con respecto al escritor puede ser más o menos grande y variar en el transcurso de la obra. (Foucault 1969: 28)

La blogonovela, como usurpación del espacio bloguero, realiza el ejercicio de impostura también del idiolecto y, a través de esto, de lo local. Es decir, el avatar se expresará empleando los rasgos regionales propios del personaje que refiere. No debe extrañarnos, por tanto, encontrar expresiones muy localistas dentro de estas obras, hecho que ha generado modificaciones necesarias en las posteriores ediciones impresas, orientadas a públicos nacionales más definidos, como en el caso de las ediciones impresas del blog Weblog de una mujer gorda -obra posteriormente conocida como Más respeto, que soy tu madre (20032004)- de Hernán Casciari, que presenta variaciones estructurales y lingüísticas en sus diferentes ediciones internacionales (Argentina, España y México). Se da, así, un predominio de lo local en el que el propio lenguaje debe ser completamente coherente con la variedad diastrática, diafásica y, por supuesto, diatópica del per- 
sonaje asumido como vertebrador de la estructura narrativa: solo así se consigue la creación avatárica que es eje de la blogonovelización.

El predominio de lo local-particular queda reflejado claramente en la imposición del idiolecto parodiado de las modelos en Diario de una miss intelijen$t e^{10}$, blogonovela escrita por Arturo Vallejo. La obra no duda, ya desde el título, en recurrir al tópico del bajo nivel formativo de este colectivo, lo que, al fin y al cabo, es también un elemento recurrente de las acciones avatáricas: forzar el hoax y, con él, la capacidad de aceptación de la realidad presentada ante los lectores. En este caso, la obra propone la historia de Marta ${ }^{11}$, una miss de pueblo que llega a Madrid tras el popular certamen de belleza de Miss España. Sus intenciones son claras: quiere triunfar en la moda y nos va contando sus aventuras y desventuras en un blog personal. Como tantas obras dentro de la blogoficción, tiene en la sátira su leitmotiv principal, ya que es un recurso empleado por el autor para explorar los límites de la credulidad de sus lectores.

En este caso, la obra deja paso a importantes marcas de oralidad mezcladas con rasgos epistolares que constituyen un aspecto recurrente junto a otros elementos específicos, como la ausencia de tildes, entre otros errores ortográficos que definen al personaje. Podemos apreciarlo, sin ir más lejos, en el capítulo "El montaje", <http://soyunamiss.blogspot.com.es/2006/04/el-montaje.html>, del 30 de abril de $2006^{12}$ :

Hola a todos y a todas,

Que hoy os voy a explicar una cosa muy mala que he hecho pero que la he hecho por necesidad y porque me lo recomendo mi manager A. F. y ahora estoy muy arrepentida porque llevo todo el fin de semana con toda mi familia llamandome por telefono y diciendome que soy una fresca [...]. (Vallejo 2006b)

Esto es una constante en toda la obra, donde también se abordan temas que podrían ser considerados tabú con el mismo desparpajo y naturalidad. Así, el 20 de octubre de 2006 se resuelve una trama previa sobre un posible embarazo por parte de la protagonista en la entrada "Que alegria al verme los chorretones" (<http://soyunamiss.blogspot.com.es/2006/10/que-alegriaal-verme-los-chorretones_20.html>). La continuidad de la trama (reforzada por

\footnotetext{
${ }^{10}$ El blog nace en la URL < http://blogs.ya.com/soyunamiss/> [no disponible] y se traslada posteriormente a <http://soyunamiss.blogspot.com.es/>.

11 Aunque el blog nace en 2005, no es hasta verano de 2006 cuando se le atribuye finalmente nombre (Marta) a la miss, con motivo de una entrevista que va a realizarse en una emisora de radio argentina. Como expone el autor, "quienes se han dedicado a husmear en la página de Miss España en busca de parecidos con la fotografía del blog han terminado llegando a la conclusión de que quien más se parece a la miss de todas las candidatas a la corona de 2005 es una chica llamada Marta. Ya que tengo que elegir un nombre cualquiera prefiero escoger uno que fomente la discusión" (Vallejo 2006a: 239). La ficha de bloguera del avatar indica que su nombre es "La más guapa": <http://www.blogger.com/profile/15272200466997424105>.

12 En todas las citas extraídas de la obra se ha optado por respetar la ortografía original sin introducir ningún tipo de corrección. Dada la proliferación de desviaciones de la norma, para facilitar la lectura no se han marcado en modo alguno -por ejemplo, con [sic]- con el objetivo de no entorpecer la lectura.
} 
la ausencia del referente anafórico inicial en el contexto inmediato) pauta una proximidad con el lector habitual, pero que se resuelve pronto aportando la información necesaria, todo ello reforzando esos aspectos de oralidad y escritura poco o nada reflexionada y, desde luego, escasamente hábil:

Hola a todos y a todas,

Que al final no lo estoy porque esta mañana que ya me iba a hacer la prueba para ver si estaba embarazada pues cuando me he despertado me he visto que tenia las sabanas manchadas y que al final eso es que me ha bajado la regla osea que he tenido mucha suerte y no estoy embarazada que habria sido muy malo que lo estuviera porque si eres una miss joven como yo que tienes aun mucha carrera por delante pues es una desgracia que tengas un niño porque ya no te cojen para desfiles si lo tienes y solo puedes hacerte fotos de embarazada como hacen algunas famosas que se las hacen desnudas pero enseñando la barriga.

Y quiero daros las gracias por los apoyos que me habeis mandado estos dias que he estado tan nerviosa pero que ahora ya no lo estoy y que de celebracion pues os pongo una foto sexy que os lo prometi si al final no me habia quedado embarazada y es una foto de este verano en la piscina que tambien hacia top less pero mejor os la pongo sin top less que tambien es sexy. (Vallejo 2006b)

Como vemos, la entrada sirve también como excusa para presentar una imagen de la protagonista, modificada con un filtro. Este retrato alterado sigue la línea de composición avatárica y las que el propio Vallejo reconoció como necesarias para la construcción de este personaje-narrador blogofictivo:

El ponerle cara al blog fue fundamental para conseguir una incertidumbre que, a su vez, se tradujese en credibilidad. Desde el primer momento la fotografía fue objeto de debate y fueron muchos los que se dejaron los ojos intentando identificar a la chica de la foto. Me preguntaron una y mil veces de qué provincia había sido miss y nunca respondí, no podía hacerlo. La fotografía en cuestión era el retrato de una modelo, creo que de origen checo, dedicada al mundo de la pornografía que encontré en Internet. Recorté su cara, reduje la calidad de la fotografía con el fin de hacerla menos reconocible y crucé los dedos para que la dueña de aquel rostro no visitara nunca mi web. (Vallejo 2006a: 6-7)

La construcción del personaje va más allá del lenguaje y los recursos fotográficos esenciales, pues la definición de la persona avatárica se ejecuta también en las opciones de configuración de la bitácora. En el caso de esta reina de la belleza resulta especialmente significativo que el blogroll13 sea denominado "Aqui pongo a algunos amigos con webs muy bonitas", toda una declaración de intenciones ingenuas y simplistas que, sin embargo, logra retratar con éxito la imagen

13 Colección de enlaces de blogs, normalmente presentada en una columna lateral. Los autores de blogs pueden definir diferentes y variados criterios para incluir otros blogs en sus blogrolls. Habitualmente, el listado de otras direcciones de blogs se compone de direcciones que los propios autores visitan con asiduidad o a veces simplemente de páginas de blogs de amigos o cercanos. 
generalizada de este colectivo en nuestra sociedad. Todo el diseño de la web se pone, de hecho, al servicio de las intenciones ficcionales del autor, pues aunque la bitácora es un espacio de publicación definido y razonablemente estandarizado, hay espacio para la personalización en múltiples aspectos (como color, tipografías, etc.), y eso define también la capacidad de uso tecnológico del avatar, así como su percepción estética del mundo:

En cuanto al diseño del blog quise que fuera tan simple como el propio personaje. En el centro de la página aparecieron mis comentarios seguidos de las réplicas de los lectores. En el margen izquierdo coloqué la fotografía de la supuesta miss seguida de esta leyenda: "Soy una miss que aunque no ha ganado Miss España creo que tengo cualidades para abrirme camino en el mundo de la moda y de la televisión que es lo que me gusta". (Vallejo 2006a: 6-7)

El autor debe, de esta manera, emplear todas las herramientas digitales a su disposición para construir la realidad del personaje avatárico y su entorno, pero también las herramientas de la narración tradicional. A las faltas de ortografía y la creación de un idiolecto propio de la miss se sumó, por tanto, la ocupación de los espacios de inscripción: descripción, fotografía, etc., para convencer al lector o, al menos, para que surja la duda. En la conquista del espacio del personaje, el avatar domina el espacio de inscripción propio del bloguero-autor hasta tal punto que es el personaje quien puede interactuar, no solo con los lectores del blog en el mismo, sino fuera de él. Esto fue puesto en práctica por Vallejo cuando en 2006 se publicó una entrevista a la protagonista (es decir, al personaje, no a él) en el diario 20 minutos. Como un actor en el escenario, el personaje se mantiene en todo momento, incluso fuera de la vida y el espacio bitacórico, porque es un acto teatral de impostura absoluta por parte del escritor, que asume e interpreta el papel del personaje que ha creado para su blogonovela. No hay, en definitiva espacio para el autor: el avatar devora la inscripción del creador, pues es este mismo en un ejercicio de interpretación total, dentro del weblog, y también en las vías de promoción de la obra. La simulación, e incluso la suplantación, del personaje sobre el autor, es total. En dicha entrevista, publicada en junio de 2006, el avatar, la modelo, suelta perlas como "Soy una mujer con algunas luces... y con sombra en los ojos cuando me maquillo. Y llevo más de un año saliendo del anonimato", o que cuando "empecé el blog quería romper el trópico de que las rubias somos tontas y podemos tener un blog y ser inteligentes... Y yo lo he conseguido, porque si pones intelijente [sic] en Google te salgo la primera" (Repiso y Hernández 2006). El propio Vallejo comenta el impacto en los medios en la edición impresa del blog, y hace referencia a esa misma entrevista:

Días después de que el blog salga reseñado en el periódico Gaceta Universitaria y de que propongan a la miss aparecer en un reportaje en la revista Glamour (reportaje que finalmente se frustra supongo que porque la reportera se da cuenta de que la miss no es más que un personaje), me entrevistan para el periódico 20 minutos. Aparezco tanto en la edición de papel como en la digital. La entrevista, que resulta bastante divertida, va ilustrada con una foto de la miss. 
Sorprendentemente, un periódico argentino se hace eco de la misma y publica una reseña contando la historia de una miss que hace furor en España gracias a un blog. Desde luego no me apresuro a desmentirlo. De la prensa, la noticia del blog de la miss española, salta al telediario del canal televisivo America 2. Ese día recibo más de diez mil visitas en mi blog y más de quinientos nuevos usuarios intentan hablar conmigo a través del Messenger. Desde ese momento Argentina se convierte en un argumento. (Vallejo 2006a: 226)

La participación del avatar en este tipo de intervenciones en los medios de comunicación se ve limitada por los requisitos de presencia física que pueden requerirse. Hernán Casciari compuso Yo y mi garrote (2006-2007) como blogonovela en la que él se encargaba de la parte textual, pero se acompañaba de unos vídeos que eran realizados por un colaborador compinchado desde el principio para encarnar esa vertiente corpórea del avatar, llamado Xavi. Además de constituir un doble ejercicio interpretativo del avatar, la presencia física de un actor encarnándolo en vídeos reforzaba el hoax más allá de lo que podría conseguirse con imágenes, como en otras blogonovelas de Casciari o en el caso de Vallejo. Sin embargo, Marta, la miss, también fue encarnada por una tercera persona en una entrevista de radio que hizo el periodista argentino Andy Kusnetzoff en 2006, en el programa Perros de la Calle (Radio Metro, Argentina). Como explica el autor, "al tratarse de una entrevista radiofónica y no escrita, tengo que recurrir a una voz femenina que me suplante en el papel de miss" (Vallejo 2006a: 239). Vallejo, tras la entrevista, decide contactar con ellos y revelar la verdad del personaje, aunque no obtuvo una respuesta por parte del presentador y ni de la productora: "Sospecho que sienten que en vez de ser ellos los que se han burlado de la miss (todo el tono de la entrevista tiene un tono burlón y despreciativo), es la miss quien se ha burlado de ellos" (239). Esta es la visión de la entrevista que aporta el autor, pero el avatar lo convierte en un fragmento de su blog: se cuelga el audio de la entrevista para su mayor difusión, y la miss la narra a su manera en la entrada 23 de junio de 2006, <http://soyunamiss.blogspot.com.es/2006/06/la-entrevista-dela-radio-que-la_23.html $>$ :

Y yo digo Hola y el me dice Hola que tal Marta que haces? y yo respondo que lo que hago es oirlos por la radio que es lo que llevo un rato haciendo porque me habian dicho que esperara y digo que oigo como juntan a la gente y como le buscan novio a los chicos y a las chicas de Argentina que es lo que habian estado haciendo la hora antes porque esa debe ser una seccion de su programa y entonces Andy se queda un poco cortado porque alomejor pensaba que yo estaba haciendo otra cosa como por ejemplo el pino o jugando al baloncesto y me responde si hacemos eso y muchas otras cosas mas ahora estamos charlando y haciendo una nota sobre la miss intelijente y el otro el del descubrimiento dice que tienen cien mil proyectos mas que a mi me parece muy bien que los tengan porque yo no habia dicho que no los tuvieran y entonces Andy sigue y me dice pero antes que nada contanos algo de vos que a si te podemos conocer o contanos algo de tu y se queda un poco callado y dice seria de tu pero en realidad esta queriendo decir de ti porque en argentina se dice el vos y en españa el tu y en vez de contanos algo de vos aqui se diria contanos algo de ti pero da igual porque Andy lo hace con muy buena intencion y yo se lo 
agradezco de mil amores y entonces sigue diciendo contanos antes de nada como se te ocurrio hacer esto y si te esperabas tener tanta repercusion y a que te dedicas y entonces yo respondo que me dedico a ser miss que es a lo que me dedico y a intentar que me vaya bien en el mundo de la television y tambien del cine y tambien de la pasarela osea la moda y le digo que los blogs son como un diario y asi que lo cree para contar las cosas que me pasan por la cabecilla y entonces andy se queda callado un poquito. (Vallejo 2006b)

La interacción del lector en la blogonovela es directa, con una influencia que será determinante en la construcción de la obra. Es un lectoautor que no puede modificar el texto (pues no cuenta con los permisos necesarios para acceder a las herramientas de publicación del blog), aunque eso no le convierte en un lector pasivo tradicional, ya que abre el diálogo directo con el avatar del autor, puede cuestionar su existencia, dar consejos, apoyarle, denigrarle..., interactuar con él como si fuera un personaje real que expone su intimidad en un blog. El avatar puede, en consecuencia, mantener ese diálogo directo con el colectivo de lectores, los visitantes de la bitácora, tanto en los comentarios (que son tan parte de la narrativa como el propio articulado) como en los artículos, a posteriori. No se trata de una hiperficción colectiva, aunque hay que señalar que sin el papel del lectoautor no hay blogonovela. El camino del personaje narrador se cruza con sus lectores, y la psique del avatar debe reaccionar ante estos, pues no puede mostrarse inerte, ya que nadie lo es, a los comentarios recibidos, aun cuando estos provienen de desconocidos que se esconden tras seudónimos y la pantalla del ordenador, al igual que el autor. El creador ha cedido el espacio de reivindicación propio al avatar. Adapta los sistemas de inscripción del blog a los del avatar, el autor/narrador ficcional, y él queda fuera, también en la relación con los lectores y los medios.

La simulación puede peligrar, precisamente, por la relación con los lectores o por colaboradores en el simulacro avatárico. En el caso del Diario de una miss intelijente, se publicó una foto de un compinchado con una chica que se dijo que era la miss, pero que era un fotomontaje. Explica Vallejo que alguien decide desvelar que el personaje no es real, sino una ficción al contar con las fotografías originales, haciéndolas públicas en el sistema de comentarios del blog. Vallejo explicó que "cada vez que lo hace censuramos sus comentarios pero su insistencia se convierte en un problema" (2006a: 212), pero esta situación se salvó cuando el otro implicado en el fotomontaje -Rafael Fernández-decidió asumir públicamente que él había sido responsable de trucar la imagen dejando como inocente a la miss, perpetuando así la simulación.

Por supuesto, la mascarada se destruye-casi siempre- en la publicación de estas blogonovelas en formato libro, donde aparece ya definitivamente el nombre del autor real, con apenas excepciones. En la edición impresa de este Diario de una miss intelijente se opta por publicar la historia con un prólogo firmado por el autor. El libro se llama Diario de una miss intelijente. Crónica de un año de no reinado y fue publicado por El Tercer Nombre en 2006. La portada indica tanto que es un blog en su origen como el nombre del autor, Arturo Vallejo. A diferencia de lo que sucedía en el blog, ejercicio de simulacro, el libro no esconde su origen 
como hoax, pero la estructura es la propia de una bitácora, con su estructura cronológica como elemento dominante. Los capítulos -las entradas del blogindican incluso la hora de publicación original y se integran los comentarios. Los visitantes son parte del libro: son lectoautores plenos a través de sus seudónimos y sus comentarios muchas veces ocupan más páginas que los breves capítulos firmados por la miss de ortografía distraída. En este caso, se respeta la ortografía de los comentarios, sin haber introducido modificaciones en los mismos, por lo que el lector no puede esperar un texto limpio. Es una traslación lo más pura posible de la bitácora al papel, donde solo la limitación física impide la integración de hipertextualidades. Arturo Vallejo, autor de Diario de una Miss Intelijente, explicó en el epílogo del blog, al presentar el libro, que:

Quienes la odiaban y quienes la amaban se lo hacían a ella, porque en ambos casos, unos y otros, se creían que el personaje era real. Me decían: "Analfabeta, vete a estudiar, inteligente es con G", y quienes eso decían se lo decían a una chica que creían tonta porque no eran capaces de darse cuenta de que un InteliJente escrito con jota en un título, no era más que una provocación. (Vallejo 2006b)

Obnubilados por la belleza de la miss intelijente, o quizá dejándose llevar por la capacidad aurática de inscripción real del diario personal, del retrato imposiblemente honesto del yo bloguero, la simulación del avatar resistió a los medios y a los lectores. El hoax queda inscrito, por tanto, en todos los niveles desde el espacio digital hasta que se destruye, finalmente, en el libro, como crónica no solo del blog, sino de los recursos empleados por Arturo Vallejo para construir el personaje: la última provocación de la miss.

\section{OBRAS CITADAS}

Adorno, Theodor W. (1951): Minima moralia. Reflexiones desde la vida dañada, trad. de Joaquín Chamorro Mielke. Madrid, Akal, 2006.

Augé, Marc (1992): Non-places. An introduction to supermodernity. Londres, Verso.

Baudrillard, Jean (2007): Cultura y simulacro. Barcelona, Kairós.

Bourriaud, Nicolas (2005): Postproduction. Culture as screenplay: How art reprograms the world. Nueva York, Lukas \& Sterling.

Brea, José Luis (1991): Nuevas estrategias alegóricas. Madrid, Tecnos.

Broncano, Fernando (2009): La melancolía del ciborg. Barcelona, Herder. (2012): La estrategia del simbionte. Salamanca, Delirio.

Carroll, Jon (2001): "The sad yet untrue story of Kaycee". En: <http://www.sfgate.com/entertainment/article/The-sad-yet-untrue-story-of-Kaycee-3314994.ph>. Última visita: 13.01.2013.

Casciari, Hernán (2006): "La ficción on line. Un espectáculo en directo". En: Cerezo, J. M. (dir.): La blogosfera hispana: pioneros de la comunicación digital. Madrid, Omán Impresores/France Telecom, pp. 171-179.

(2003-2004): ¡Más respeto, que soy tuy madre! En: <http://mujergorda.bitacoras. com>. Última visita: 13.01.2013. 
Castronova, Edward (2006): Synthetic Worlds. The Business and Culture of Online Games. Chicago, The University of Chicago Press.

Cleger, Osvaldo (2010): Narrar en la era de las blogoficciones. EE. UU., The Edwin Meller Press.

Cooper, Robbie y Dibell, Julian (et al.) (2007): Alter Ego. Avatars and their creators. Londres, Chris Boot.

Dery, Mark (1998): Velocidad de escape. La cibercultura en el final del siglo, trad. de Ramón Montoya Vozmediano. Madrid, Siruela.

Echeverría, Javier (2003): "Cuerpo electrónico e identidad". En:Hernández Sánchez, D. (ed.): Arte, cuerpo, tecnología. Salamanca, Ediciones Universidad de Salamanca, pp. 13-29.

Escandell Montiel, Daniel (2010a): "El escritor convertido en actor: el blogonovelista en su teatrillo". En: Despalabro. Ensayos de Humanidades, vol. IV, pp. S39-S43.

(2010b): "The Writer Seeking Vengeance: Blognovelism and Its Relationship with Literary Critics". En: Bibb, S. C. y Escandell, D. (eds.): Best Served Cold. Studies on Revenge. Oxford, ID-Press, pp. 127-136.

Feldman, Marc (2000): "Munchausen by Internet: Detecting Factitious Illness and Crisis on the Internet". En: Southern Medical Journal, vol. 93, n. ${ }^{\circ}$ 7, pp. 669-672.

Feldman, Marc, Bibby, Maureen y Susan Crites. D. (1998): "«Virtual» factitious disorders and Munchausen by proxy". En: Western Journal of Medicine, vol. 168, n. ${ }^{\circ}$ 6, pp. 537-539.

Foucault, Michel (1969): ¿Qué es un autor? Buenos Aires, Ediciones literales.

Hafner, Katie (2001): "A Beatiful Life, an Early Death, a Fraud Exposed". En: <http://www. nytimes.com/2001/05/31/technology/a-beautiful-life-an-early-death-a-fraud-exposed.html?pagewanted=all\&src=pm>. Última visita: 29.12.2012.

Hammond, Graeme (2001): "Fooled by a web of lies". En: Sunday Herald Sun, 27 de mayo, p. 11.

Kottke, Jason (2004): "Seems that Plain Layne 'is' a hoax". En: <http://kottke.org/04/06/ plain-layne-update>. Última visita: 29.12.2012.

Laddaga, Reinaldo (2007): Espectáculos de realidad. Ensayo sobre la narrativa latinoamericana de las últimas dos décadas. Rosario, Beatriz Viterbo Editora.

Lankshear, Colin y Knobel, Michele (2008): Nuevos alfabetismos. Su práctica cotidiana y el aprendizaje en el aula. Madrid, Morata.

Latour, Bruno (1991): Nunca fuimos modernos. Ensayo de antropología simétrica. Buenos Aires, Siglo xxI.

Meadows, Mark Stephen (2008): I, Avatar. Berkeley, New Riders.

Mora, Vicente Luis (2006): Pangea. Sevilla, Fundación José Manuel Lara.

Repiso, L. y Hernández, C. (2006): "Miss Intelijente: «Cuando empecé el blog quería romper el 'tópico' de que las rubias somos tontas». En: <http://www.20minutos.es/noticia/128840/0/intelijente/blog/miss/>. Última visita: 29.12.2012.

Rodríguez Marcos, Javier (2011): "Los peligros de 'rehacer' la obra literaria de Borges". En: <http://cultura.elpais.com/cultura/2011/10/01/actualidad/1317420001_850215. html>. Última visita: 29.12.2012.

Shirobara (2001): "The Life and Death of a False Warrior". En: <http://www.kuro5hin.org/?o $\mathrm{p}=$ displaystory;sid=2001/5/22/11120/1650 > Última visita: 29.12.2012.

Sibilia, Paula (2008): La intimidad como espectáculo. El Salvador, Fondo de Cultura Económica. 
Simmel, Georg (2000): "El conflicto de la cultura moderna". En: Reis, n. 89, pp. 315-330.

Stephenson, Neal (2003): Snow Crash. Nueva York, Bantam Spectra.

Tisseron, Serge (2001) : L'intimité superexposée. París, Ramsay.

Tomas, Maximiliano (2012): "Que nadie se atreva a tocar a mi Borges: María Kodama y la industria del juicio". En: <http://www.lanacion.com.ar/1465418-que-nadie-seatreva-a-tocar-a-mi-borges-maria-kodama-y-la-industria-del-juicio>. Última visita: 10.01.2013.

Turkle, Sherry (1998): "Repensar la identidad de la comunidad virtual". En: El Paseante, n. ${ }^{\circ}$ 27-28, pp. 48-51.

Vallejo, Arturo (2005-2006): Diario de una Miss. En: <http://blogs.ya.com/soyunamiss/>. Última visita: 3.09.2011.

_ (2006a). Diario de una miss intelijente. Madrid, Editorial El Tercer Nombre. (2006b): Diario de una Miss Intelijente pero el segundo año. En: <http://soyunamiss. blogspot.com/>. Última visita: 13.01.2013.

Wark, McKenzie (2007): Gamer Theory. Cambridge, Harvard University Press. 